\title{
The Metro Project Construction Safety Risk Managing System of GMC
}

\author{
Guangwu Liu, Fengxia Luo, Gang Zeng \\ Guangzhou Metro Corporation, Guangzhou, China \\ Email: liuguangwu@gzmtr.com
}

Received 26 June 2013; revised 12 February 2014; accepted 24 February 2014

Copyright (C 2014 by authors and Scientific Research Publishing Inc.

This work is licensed under the Creative Commons Attribution International License (CC BY). http://creativecommons.org/licenses/by/4.0/

(c) (i) Open Access

\begin{abstract}
Based on the international vulgate safety risk managing theory, the Guangzhou Metro Corporation (GMC) summarizes the standard system of safety risk management in metro rail transit project, integrating with criterion files about project on safety risk management promulgated by the Ministry of Housing and Urban-Rural Development of the People's Republic of China (MOHURD), according to the project practice. The result of application indicated that this system, which has been popularized in several other Chinese cities, effectively guaranteed personnel and project safety, and promoted the safety risk managing level of project participators in the same time.
\end{abstract}

\section{Keywords}

Standardization; Metro Rail Transit Project; Safety Risk Managing System

\section{Introduction}

Currently, metro rail transit projects are growing rapidly in China. According to statistics, there are fifteen cities operating metro up to May 2013 with the total mileage of 2416 kilometers, Beijing, Shanghai and Guangzhou are three of the top ten cities that have operating mileage in the world. At the same time, there are thirty-six cities developing metro rail transit projects with the total mileage of 1370 kilometers, the total budget of which will be about 1200 billion Yuan. However, the safety risk rose synchronously with development in the last several years. From 1999 to 2010 media reports, ninety-two accidents happened in metro rail transit projects, sixtyeight people died from these accidents and direct economic losses stood at least 4.1 billion Yuan.

In Guangzhou, the metro rail construction entered fastigium in recent years. At the most, eight subway lines were constructed simultaneously with more than 200 construction sites and eighty shield machines tunneling, which was rare in the whole world. Foundation ditch with the depth of 34 meters and silo with the depth of 42 meters caused great construction difficulties. Considering the very complex geological conditions of sand layers, 
Karst, mollisol, hard rock and fractures coexisting in Guangzhou region, large-scale subway construction in all probability had a destructive impact on environment, causing ground subsidence, houses tilt or pipelines damage.

Obviously, traditional safety management pattern was dependent on people's experience and thus hard to cope with serious safety situation. It is urgent to start research on safety risk management system, technology and relevant standards. Since 2005, Guangzhou Metro Corporation (GMC) started the research and application on safety risk management as the lead of Chinese metro corporations [1]. In November 2010, the Ministry of Housing and Urban-Rural Development of the People's Republic of China (MOHURD) authorized GMC to carry out the pilot project of "Metro Rail Transit Construction Risk Evaluating and Application Research". Utilizing the international common risk management theory, preliminary design as the starting point of risk evaluating, and Line 9 being the experiment bed, the practicability of the construction of safety risk management standard was validated. According to research, application and innovation, GMC induced the safety risk management system of "six times evaluating, six-party management and an unified platform". This system was applied in the construction of Line 2, the northern extended section of line 3, Line 5, Line 6 and Line 9 of GMC, furthermore, the system was integrated with criterion files about safety risk managing project promulgated by the MOHURD, which has been popularized in more than ten other Chinese cities such as Shenzhen, Xi'an, Dongguan, Hefei, Kunming and Changchun. Therefore, significant benefits were obtained.

\section{The Safety Risk Management Theory, Method and System Standardization}

As huge systematic engineering, how to manage metro rail transit projects risks is a challenging task. Usually, the risks fall into two categories according to international common risk management theory: technical risks and planning risks. The former includes those risks probably result in projects unable up to performance standards, the latter includes cost overruns and schedule delayed [2].

Metro rail transit construction safety risk is part of technical risks. In general, there are several principles which should be followed. First of all, every party relevant to the project should participate in the safety risk management, such as the government, the metro rail transit projects owners, the design institutes, the construction companies, the supervision companies and the third party monitoring companies. Secondly, the safety risk management should run through the lifecycle of metro rail transit projects, regardless of stages of feasibility study, prospecting, design, construction and trial operation. Thirdly, cyclically monitoring and testing the key safety risks must be sustained. Finally, safety risk management participators should constitute task force for purpose of sharing their professional knowledge, moreover sharing rewards or undertaking punishments linking up to success or failure [3].

Based on the above safety risk management principles, we consider it is necessary and feasible for metro rail transit projects to establish scientific and standardized safety risk management system. Although every project has unique characteristic, principles are universal. Principles solidified thus a series of tools, methods and procedures derived, when they had been completed enough the standardized system formed. The standardized procedures of safety risk management could be as follows: First of all, risks recognizing. It means to find the causes and possible results of safety problems. Secondly, risks filtering. The key risks are filtered and sorted. Thirdly, risks evaluating. After key risks are recognized and filtered, they should be deeply analyzed and measured. Finally, risks managing. After key risks are evaluated, all participators should seek feasible means to prevent, reduce, shift them or accept them. According to costs, risks, benefits and other basis, those means are selected, at the same time the second risks caused by those means must be considered. The output of the safety risk management procedures is one group of plans to control the key risks of the project.

There are many tools and methods with the help of which we manage safety risk of metro rail transit projects. For example, we recognized geological risks by means of collecting geological data, locale inspecting or geophysical prospecting; we evaluated risks by means of score table based on experts' opinion; we used the alarm and emergency information platform to gather, distribute and process risk information, even aid decision making.

In order to regulate the engineering projects safety risk management, the Ministry of Housing and Urban-Rural Development of the People's Republic of China (MOHURD) enacted a series of laws and regulations, including “Metro Rail Transit Construction Projects Safety and Quality Management Interim Provision', “Metro Rail Transit Underground Construction Projects Risks Management Criterions”, "Metro Rail Transit Risk Eva- 
luating Guid”, etc. Applying international common theories, and guided by MOHURD’s criterions, through research and innovating, from the project practice the Guangzhou Metro Corporation (GMC) summarized a effective system of safety risk managing, which was arranged as "six times evaluating, six-party management and an unified platform”. Figure 1 represents the framework of this system in detail, Figure 2 represents the implementing procedures of this system in detail. Next in this paper, the system will be elaborated, subsequently the successful case of GMC Line 9 construction safety risk management applying this system will be analyzed.

\section{The Safety Risk Management System of GMC-“Six Times Evaluating, Six-Party Management and an Unified Platform"}

The system of "six times evaluating, six-party management and an unified platform" is based on three aspects: international common risk identification, evaluation and management theory, method or tools; a series engineering projects safety risk management criterions enacted by MOHURD; GMC's practice of construction safety risk management.

Thereinto, "six times evaluating" means preliminary evaluating and the lasting risk identification and evaluating throughout the life cycle; "six-party management" means all parties relevant to the project should participate in the safety risk management, such as the government, the metro rail transit projects owners, the design institutes, the construction companies, the supervision companies and the third party monitoring companies; "an unified platform” means the online "Guangzhou Metro Safety Risk Coordinated Disposal Platform".

As for "six times evaluating", the metro rail transit projects owners is the subject, which embodies the principle of safety risk management should run through the lifecycle of metro rail transit projects. More specifically, safety risk should be identified and evaluated at stages of before the project, feasibility study, design, construction, utilizing new technologies and trial operation.

Evaluating safety risks before projects involves every aspect of the safety management system, including safety managing organization system and its running, system of responsibility for safety, system of safety management, safety technologies, safety education and training, significant risk sources, emergency rescue and the third party monitoring, etc.

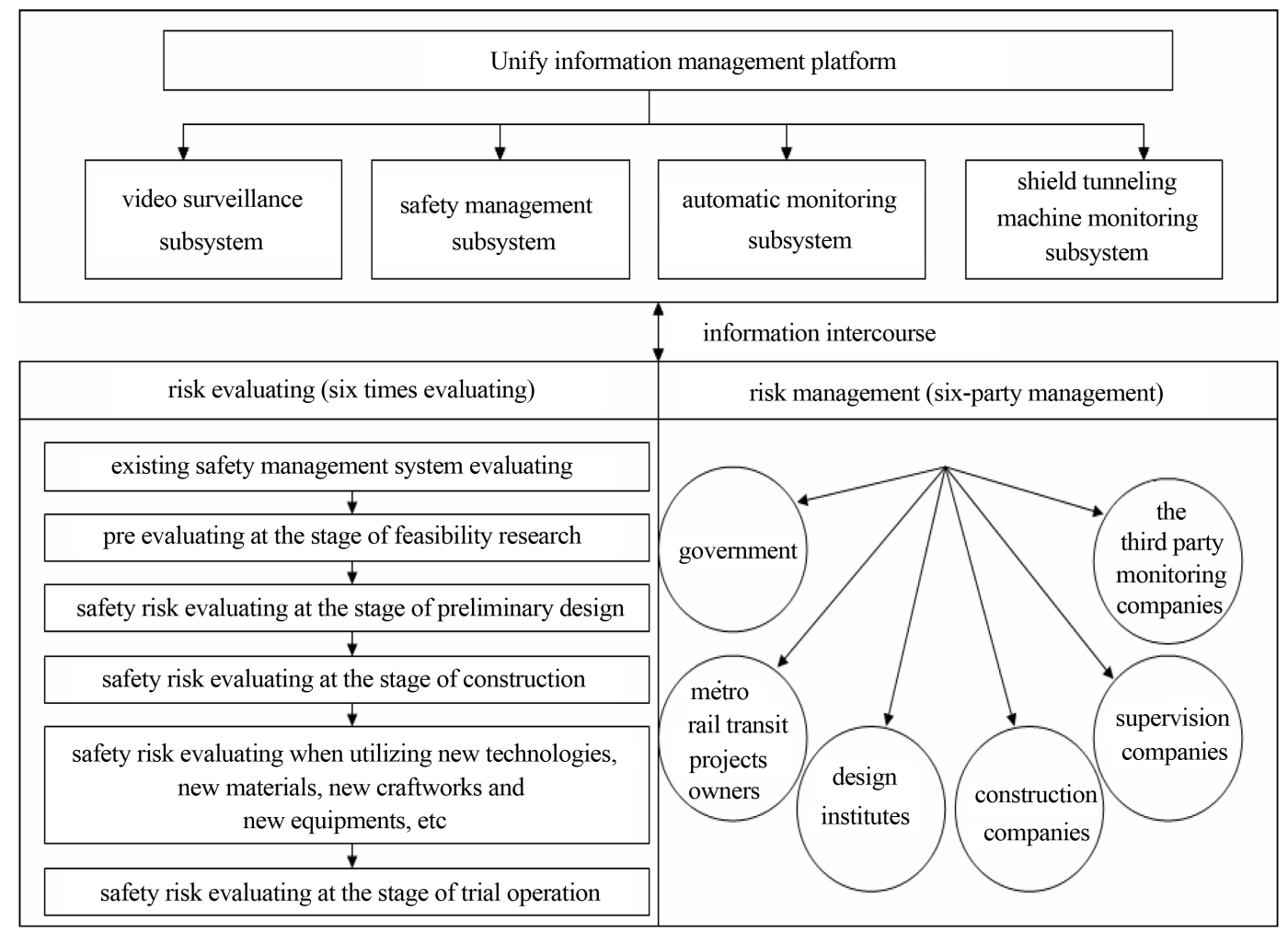

Figure 1. The framework of GMC’s safety risk management system. 


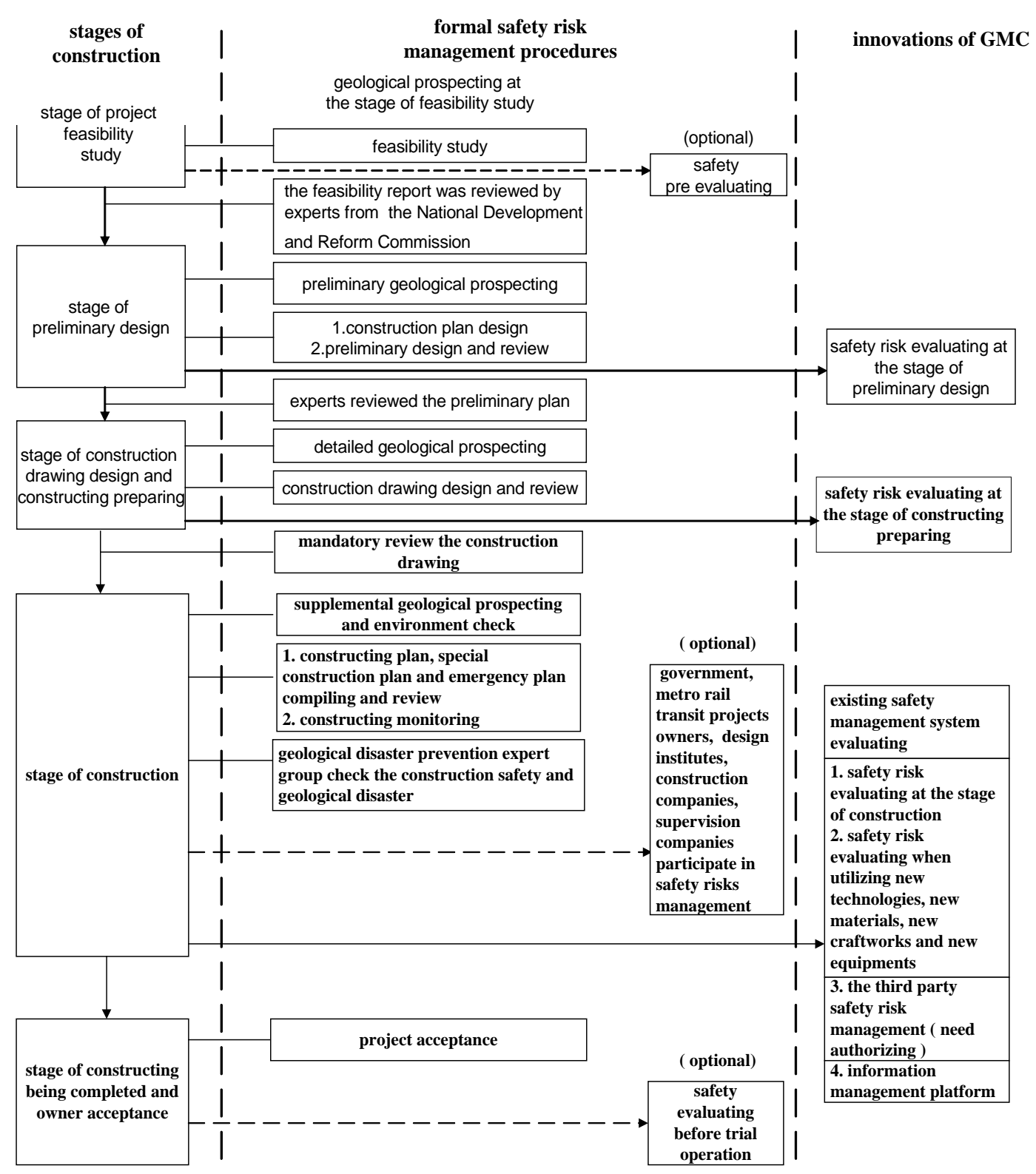

Figure 2. The implement procedures of GMC’s safety risk management system in detail.

Evaluating safety risks at the stage of feasibility study involves constructing labor safe preliminary assessment, rail transit system safety checklist assessment, rail transit construction significant safety risk effect analysis and assessment, environment safety analysis and assessment, large passenger flow of typical underground stations evacuating analysis and assessment, typical underground stations and sections fire smoke preventing and crowd evacuating analysis and assessment, typical underground stations and sections tunnel surrounding rock stability analysis and assessment, etc.

Evaluating safety risks at the stage of preliminary design involves foundation ditch construction, section tunnel construction, viaduct section construction and preliminary key point special evaluation, etc.

Evaluating safety risks at the stage of construction highlights the characteristic of running through the lifecycle of metro rail transit projects, which is closed loop and divided into several links. Specifically, through cyclical analyzing monitoring data from typical construction sites, risks and risk sources are listed, then in contrast to safety risk classifying and grading standards, current constructing process safety risk grade is evaluated, based on which risks control measures or advice are provided. Finally, how these control measures impact on moni- 
toring data from typical construction sites is inspected.

When utilizing new technologies, new materials, new craftworks and new equipments, risks due to inexperience or undiscovered risks should be evaluated, it is also one procedure of "six times evaluation". The evaluating procedure includes combining past engineering design, construction cases, analyzing experience and lessons, recognizing risk resources and potential risk affairs, analyzing and assessing risk probability and risk damage, then finding key problems need solved and risk avoiding or controlling measures and advice.

Safety assessing before trial operation means safety check and laws conformity assessment about relevant construction sites, such as safety analysis and assessment about every system, normal protecting equipments or infrastructures assessment, fire safety and explosion-proof measures assessment, electrical safety measures assessment, special equipments and mandatory testing equipments checking and assessment, safe operation managing assessment, etc.

As for "six-party management", all parties relevant to the project are the subject, which embodies the principle of all parties relevant to the project should participate in the safety risk management according to their duties, including the government, the metro rail transit projects owners, the design institutes, the construction companies, the supervision companies and the third party monitoring companies. At the same time, it meets the requirement of MOHURD’s regulations.

Being owner, GMC manages metro rail transit construction safety risks in the round, such as technical and environment risks (geological risks, construction risks, environment risks), management risks, economical risks, contract risks, etc. As the subject of management, the owner's representatives and inspectors often inspect construction sites; the geological disaster prevention expert group often review constructing plans and inspect construction sites; main employee or expert teams are often organized to investigate risks and evaluate safety risks.

If necessary, GMC is likely to authorize the third party companies to manage safety risks. For example, when encounter with geological risks, environment risks or very professional construction risks, GMC may authorize experts or qualified consulting companies to participate in safety risk evaluation, or authorize qualified consulting companies to participate in the third party safety risk management throughout construction process, or authorize qualified monitoring companies to participate in the third party monitoring throughout civil engineering process.

As for “an unified platform”, it means the "Guangzhou Metro Safety Risk Coordinated Disposal Platform”, over which "six times evaluating” and "six-party management” carried out. Past safety risk management information system mainly focus on problems in construction progress, GMC's platform focus on progresses of feasibility research, prospecting, design, construction, trial operation, and enable parties relevant to the project coordinated disposal, which is the innovative feature of this platform [4].

The functions of the "Guangzhou Metro Safety Risk Coordinated Disposal Platform” are as follows:

(1) Achieve information management about "six times evaluating”.

(2) Achieve safety management information shared by parties relevant to the project and work record scared; enable parties relevant to the project coordinated dispose of safety rectification, monitoring alarm, inspecting alarm and emergency; remote online assess safety management of parties relevant to the project, etc.

“Guangzhou Metro Safety Risk Coordinated Disposal Platform” also implements the automated real time monitoring system integrated with GIS display technology. The functions of this system includes automated gathering and remote transferring field data, data mining, intelligent analyzing, real time alarm and GIS intuitive display, etc.

\section{Case Analysis of GMC Line 9 Safety Risk Evaluating at the Stage of Preliminary Design}

The overall length of Guangzhou metro rail Line 9 is $20.119 \mathrm{~km}$, all the Line 9 is underground, with one access line, nine underground stations, and nine sections. The construction methods included cut and cover method, shield method and mine tunneling method. Along this line, the geological risks are Karst caves, fractures, soft soil, sand layers, rock softening, rock hardness uneven, high groundwater levels, etc. Meanwhile, environment risk sources are the high-speed rail from Wuhan to Guangzhou, Tianmei River, etc. The significant difficulties are as follows: Firstly, Karst caves. Too many caves are distributed along Line 9, the ratio is up to 64\%, that greatly increased the risk of construction. Secondly, the shield tunneling machines pass through under a large number of buildings and structures, highways and rivers. In especial, the shield tunneling machines pass through 
under the high-speed rail from Wuhan to Guangzhou, where thick sand layer exists. When constructing plan was reviewed, the owner of high-speed rail required zero sedimentation, which was very difficult. All the above significant risk sources had been identified before the start of project, at the stage of preliminary design every party relevant to the project evaluated the construction risks based on the safety risk management system elaborated in this paper.

As the owner of project, GMC organized prospecting companies and designing companies to evaluate safety risks. For significant risk sources as Karst caves and passing through under high-speed rail, the third party companies were authorized to provide monographic study reports, followed by experts being organized to review these reports. For Karst caves risks, several academicians of the Chinese Academy of Engineering were invited to research possible risks at the stages of construction and operation. As for the significant environment risk of pass through under the high-speed rail, special design and construction plan were provided based on monographic study. In April 2011, this special design and construction plan was formal reviewed by experts from all over the country.

For the geological risks of fractures, prospecting companies specially prospected through complex geophysical prospecting supplemented by indoor tests and bailing experiments. As for ground water risks, ground water isotopic tests was utilized to check and analyze the flow direction and flow velocity of ground water. The ground water distributing features were also monographic studied.

For the Karst caves risks, special design and constructing advices were provided by designing companies. The designing companies checked and evaluated significant risks of Line 9 project, and the preliminary design of Line 9 passed experts' preliminary review in October 2009.

The safety risk management team synthesized above risk evaluation work, according to risk evaluation procedure, method and technical standards, assessed the grade of all Line 9 constructing sites, and discovered two sites with risk level 1, one site with risk level 2, seven sites with level 3 and five sites with level 4 . Therefore, risk controlling plan was constituted, risks of project or environment were avoided, reduced and controlled from the source at the stage of preliminary design. For significant risks, response measures were provided, avoiding latent dangers due to constructing companies being short of risks preventing measures and cost after winning the bidding.

\section{The Application Achievement of GMC’s Safety Risk Management System}

The implementation of "six times evaluating, six-party management and an unified platform" eliminated or weakened lots of significant risk sources of GMC construction projects effectively. Statistics indicates that the ratio of significant risk sources being successfully eliminated is $94.2 \%$; instead, the ratio of significant risk sources causing substantial damage is only $5.8 \%$. This achievement ensures safety of staffs relevant to construction directly and effectively, deduces direct economical damage and schedule delayed, and protects city's environment and resources.

In short, being a successful case, the implementation of the safety risk management system elaborated in this paper is an active exploration and valuable experience for standard safety risk management to be promoted in the sector of metro rail transit in China.

\section{References}

[1] Liu, G.W. (2007) Innovate Safety Management to Build Safe and Harmonious Enterprise. City High-Speed Rail Transit, 20, 34-40.

[2] Chapman, R.J. (2001) The Controlling Influences on Effective Risk Identification and Assessment for Construction Design Management. International Journal of Project management, 19, 147-160.

[3] FHA (1999) Asset Management Primer. Office of Asset Management, U.S. Department of Transportation, Federal Highway Administration.

[4] Liu, G.W. (2011) The Research and Application of GMC Safety Alarm and Emergency Platform. Modern City Rail Transit, 18-21. 